ISSN: 0212-5099

DOI: https://doi.org/10.24310/BAETICA.2018.v0i38.5559

\title{
CAPITALIZACIÓN Y ACTIVIDADES INCONFESABLES DE UN BURGUÉS MALAGUEÑO EN EL SIGLO XIX
}

\author{
Alfredo IbáÑez Linares* \\ Universidad de MÁlaga
}

\begin{abstract}
RESUMEN
A través del origen de la capitalización de Jorge Loring Oyarzábal y de su actividad empresarial en prácticas "mal vistas" por la sociedad de su tiempo, pretendo colaborar al conocimiento de las elites económicas malagueñas de mediados del siglo XIX. Busco las contradicciones que inevitablemente surgirán con los planteamientos liberales, tanto económicos como sociales y morales de esa burguesía, en momentos de abundancia económica y liderazgo fabril y comercial de Málaga. He investigado en las herencias de las familias Heredia y Loring, dote de la mujer (Amalia Heredia) y las escrituras de las compañías de los Loring que confluyen en la capitalización inicial del personaje. Respecto a sus "actividades inconfesables" como prestamista y esclavista, descubro que no son tan excepcionales entre el mundo empresarial del periodo.
\end{abstract}

PALABRAS CLAVE: burguesía, Málaga, siglo XIX, capitalización, prácticas comerciales

*aibanez155@gmail.com

(C) Baetica. Estudios Historia Moderna y Contemporánea, 38, 2018, 193-225. Facultad de Filosofia y Letras, Universidad de Málaga. Departamento de Historia Moderna y Contemporánea 


\title{
CAPITALIZATION AND UNSPEAKABLE ACTIVITIES OF A 19TH-CENTURY BOURGEOIS FROM MALAGA
}

\author{
Alfredo IbÁÑez Linares* \\ Universidad de Málaga
}

\begin{abstract}
In this dissertation I will modestly intend to contribute to the understanding of the mid-19th Century economic elite in Malaga by approaching the origin of Jorge Loring Oyarzabal's capitalization and economic activity, commonly frowned upon by the society of his times. This way I will highlight the contradictions with the liberal principles, in social, moral and economic terms, during times of economic plenty and business and trading leadership in Malaga. To do so, I have researched into the inheritance of both Loring and Heredia families, his wife Amalia Heredia's dowry and the Loring's company deeds that converge on Mr Loring's initial capitalization. As for his "shameful activities "as a loanshark and a slavedriver", I find that it was not such an uncommon practice in the trading business of those times.
\end{abstract}

KEYWORDS: bourgeoisie, Malaga, 19th century, capitalization, trading activities 
Sobre Jorge Loring Oyarzábal no existe demasiada bibliografía, pues carece del protagonismo de otros malagueños contemporáneos: el político de Antonio Cánovas y el empresarial de Manuel Agustín Heredia o Martín Larios. Sus virtudes las elogiaban el gobernador Guerola en las memorias ${ }^{1}$, el joven Cánovas desde el escaño cuando le defendió por su españolidad o desde la prensa local tan propensa al incienso. Ese retrato laudatorio se completa con los restos monumentales de Jorge Loring que permanecen: la antigua fachada de la estación del ferrocarril, el jardín de la Concepción, la Lex Flavia Malacitana del Museo Arqueológico Nacional y otras piezas incluidas en el Museo de la Aduana.

Este legado patrimonial y cultural corrobora lo que Nietzsche denomina "historia monumental", mediante la que el cronista da un sentido memorable a lo pasado, al relato de una gesta, que al llegar al presente nos conforta. Esa concepción de la historia, en general compartida por los escasos biógrafos locales, la voy a contraponer a una "biografía crítica" motivo de mi proyectada tesis doctoral. Con ese objeto pretendo, a través de este estudio, contrastar la imagen del burgués malagueño triunfante, "capitán de empresa o de industria", con el origen de la capitalización y de dos actividades comerciales que contradicen el retrato oficial. Con esa categoría de capitán aludo a la apología al empresario de Schumpeter, como burgués innovador e inversor constante y calculador, dotado del ideal de conquista, o del gozo creador de fundar un reino privado ${ }^{2}$.

La bibliografía existente nos ofrece un relato lineal. Jorge Loring Oyarzábal (1822-1900) nacido en Málaga de padre norteamericano, recibió educación universitaria en Boston. En 1850 se casa con Amalia Heredia Livermore, gracias a ello se inserta en la llamada "oligarquía de la Alameda". En la década de los cincuenta es nombrado marqués, participa en la fundación del Banco de Málaga y el periódico El Correo de Andalucía, compra la finca de la Concepción y los bronces romanos de la Lex Flavia Malacitana y de Salpensa. Es elegido diputado y se le adjudica el ferrocarril Córdoba a Málaga, dedicando los años sesenta fundamentalmente a construir y explotar este, y a la actividad política.

1. A. Guerola (1995), 246.

2. J. SChUMPeter (1976), 38.

(C) Baetica. Estudios Historia Moderna y Contemporánea, 38, 2018, 193-225. Facultad de Filosofia y Letras, Universidad de Málaga. Departamento de Historia Moderna y Contemporánea 


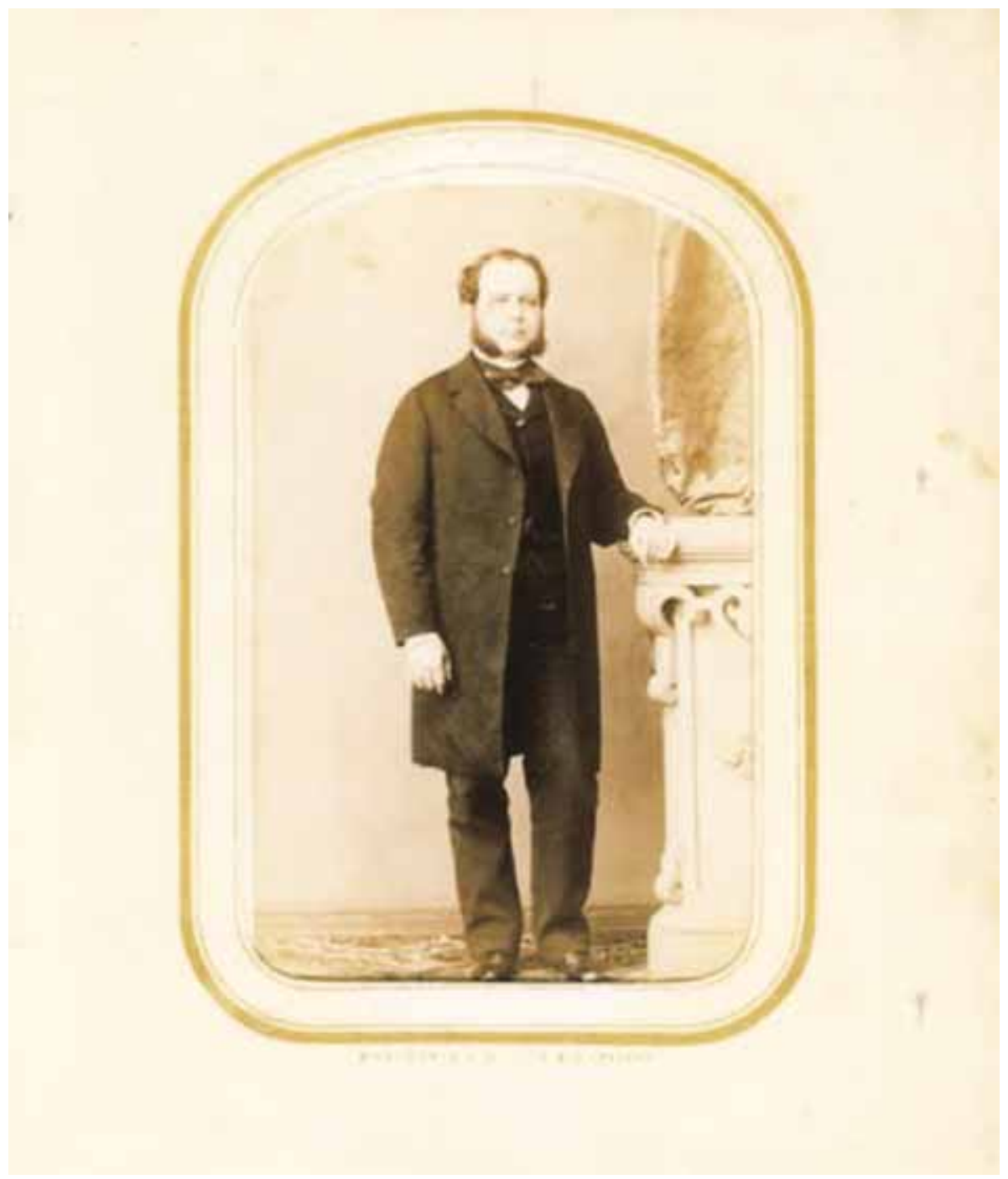

Imagen 1. Jorge Loring Oyarzábal. Foto de tarjeta de visita, Archivo Díaz de Escovar. 


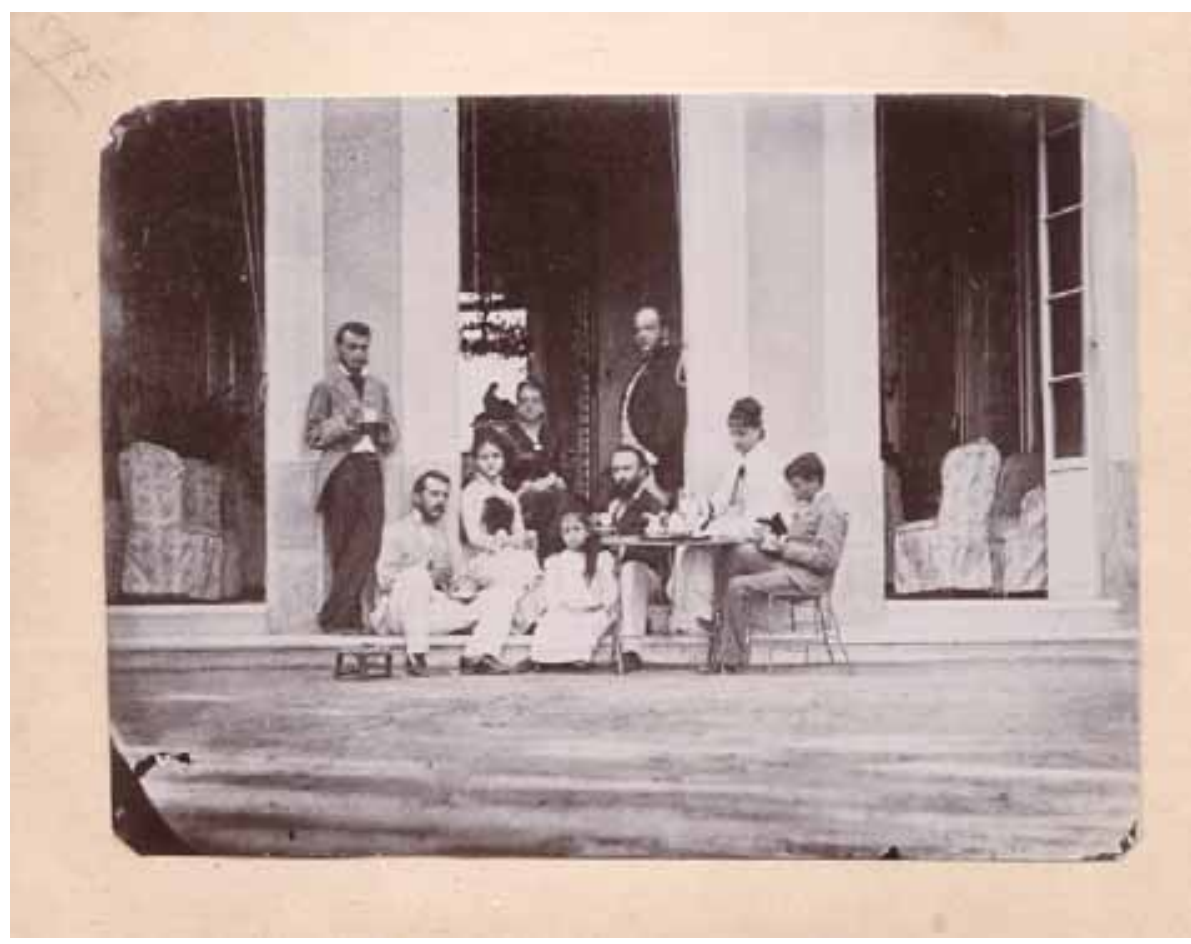

Imagen 2. El matrimonio Loring a la puerta del salón de la Concepción. Álbum familiar de Tomás Heredia.

Durante el Sexenio Democrático apoyó a su amigo Cánovas del Castillo en las conspiraciones cortesanas previas a la Restauración. La llegada de esta le hizo volver a las Cortes, aunque por una sola legislatura, después abandonó la política. Dedicó grandes esfuerzos a las operaciones especulativas con los ferrocarriles, especialmente a la creación de Ferrocarriles Andaluces. Gracias a la rápida compraventa de líneas ferroviarias consiguió su mayor poder económico, lo que le permitió diversas inversiones. Además del ferrocarril, intervino en minería, agricultura (esparto y madera), sector inmobiliario... En los años noventa fue senador vitalicio, murió con el nuevo siglo. Según su mujer en la ruina debido a un negocio de minería ${ }^{3}$.

3. M. Morales (2010), 158-159; M. V. Campos Rojas (2006); E. M. Ramos Frendo (2000), 56; J. A. JiMÉNEZ Quintero (1977), 42-45. 
Para confrontar esa narración, en este trabajo empleo fuentes primarias: las actas notariales del Archivo Histórico Provincial de Málaga (en adelante AHPMa), los legajos del Archivo Histórico Nacional (AHN) de las correspondencias consulares y una carta facilitada por Jorge Benthem, descendiente del ferroviario. Respecto a las primeras, las más utilizadas son las de herencias (inventarios post-mortem) y dotes matrimoniales, ya empleadas por los historiadores sociales franceses de los años setenta del siglo pasado ${ }^{4}$. El profesor antequerano Parejo Barranco defendía, una década después, los protocolos notariales frente a los fiscales como más fiables para el empleo en la Historia Industrial. Los caracterizó en cuatro tipos de los que tres he utilizado en este trabajo ${ }^{5}$. Por lo que se puede deducir una utilización de fuentes primarias no excesivamente novedosa, pero sí perfectamente contrastada por la metodología de la investigación histórica actual.

La acepción de burguesía empleada en el título de este estudio, corresponde a aquella clase social compuesta por comerciantes, fabricantes, banqueros, empresarios y directores. Es decir, la que Jürgen Kocka denominó "burguesía estricta", diferenciada en su clasificación de la burguesía ilustrada y de las clases medias. Este autor considera que ese concepto de burguesía no es válido aplicarlo a la actualidad, aunque sí lo defiende para el siglo XIX. El proyecto burgués consistía en una sociedad utópica formada por ciudadanos libres, autosuficientes e iguales, capaces por sí mismos de regular su vida colectiva razonablemente. El "modo de vida burgués" definió una clase social concreta, que admitió a la antigua nobleza convirtiéndola, y dejándose cautivar por ella; y a la vez influyó en la clase media como referente, aburguesándola ${ }^{6}$.

Tres historiadores españoles me han influido decisivamente para armar historiográficamente este artículo. El profesor valenciano José Antonio Piqueras defiende el estudio de los procesos políticos y sociales que nos conduzcan al conocimiento, tanto de las contradicciones de los intereses de clase, como de los colectivos que compiten entre sí (por el salario o por el mercado) característicos de la sociedad capitalista. Concibe al ochocientos como el siglo ideal donde estudiar el liberalismo económico, pues es donde nace y se desarrolla, pero también donde a la postre acaba la libre competencia, cercenada por las grandes corporaciones?

4. A. Daumard (1973), 588.

5. J. A. Parejo Barranco (1984), 337-374.

6. J. KockA (2000), 22-62.

7. J. A. Piqueras Arenas (1998), 19. 
No entran en la refriega los profesores valencianos Pons y Serna, pero presentan la Europa del siglo XIX como el triunfo del mundo burgués, dedicado a la fabricación y al mercadeo. Estos mercaderes prosperaban luchando contra la competencia, con el riesgo como bandera; y en su discurrir vital generaron un "modo de vida burgués" entre los años cuarenta y sesenta. En lo político controlaban un "ámbito de notables", con sufragio restrictivo, convirtiendo ciertas instituciones en su patrimonio personal. No todos pueden ser burgueses, pero sí pueden adquirir las cualidades que les son propias, por ello no sólo es el siglo de la burguesía, sino también del aburguesamiento. Los profesores valencianos no entran a juzgar los comportamientos y los hechos de los burgueses sino que los muestran para que el lector decida los que son asimilables al mundo actual. Metodológicamente, reducen la escala del objeto de estudio (microhistoria), pudiendo así analizar mejor sus comportamientos (historia cultural) ${ }^{8}$.

No es otro el objetivo de este artículo: a través de la lupa de la microhistoria sobre los Loring, de los orígenes y actividades económicas que contravienen la historia monumental del personaje, aportar elementos al perfil de una clase dirigente característica de la época que le tocó vivir. Las contradicciones que surgirán me servirán a la hora de establecer conclusiones en este banco de pruebas que nos ofrece la metodología histórica. Con ello no pretendo ocultar los aspectos positivos del personaje y la clase social que él representa (interpretados como capitanes de empresa o prohombres benefactores por la mayoría de los autores malagueños que se han ocupado del tema) sino mostrar con visión crítica al personaje y sus contradicciones.

¿Loring tuvo unas peculiaridades comunes a otros burgueses españoles? Para estudiarlo las compararé con las de otras capitales española (Barcelona, Valencia, Gijón y Sevilla) a la vez que analizaré cómo encaja Loring y la burguesía malagueña en las teorías historiográficas inglesas. Sin olvidar la singularidad del personaje que acentúan el interés de la narración histórica. 


\section{EL ORIGEN DE LA CAPITALIZACIÓN O EL JUEGO DE LAS HERENCIAS}

\subsection{La herencia paterna}

El origen de la capitalización de Jorge Loring Oyarzábal hay que buscarlo en la herencia familiar. Al año siguiente de la muerte del padre, George Loring James, se produjo el reparto testamentario el 6 de julio de 1844. Antes se hizo el inventario post morten y la contabilidad de la casa de comercio Jorge Loring y Cía. El concepto de sociedad familiar o "casa de comercio familiar", es un término muy empleado en Málaga, amparado en una idea patriarcal de que los hijos eran la segunda existencia del padre. En Cataluña la relación familia-fábrica se establecía en la denominada "casa industrial", donde se incorporaban los hijos conforme adquirían la mayoría de edad. La firma individual familiar fue un trampolín desde el que las elites catalanas diversificaban las posesiones y establecían asociaciones con otras familias 9 .

El Código de Comercio de 1829 establecía tres modalidades de sociedades: regular colectiva, en comandita y la sociedad anónima. En la regular colectiva, los socios se repartían el capital social y la dirección de la empresa; la mayoría de las empresas familiares son colectivas en Cataluña. La sociedad en comandita, se caracterizaba por que el socio comanditario aportaba la mayoría del capital, el resto de los socios colectivos administraban la compañía. Con la sociedad anónima, se crea un fondo de capital por acciones de la empresa, que manejan mandatarios o administradores a voluntad de los socios. Hasta 1868 no se liberalizaron las sociedades anónimas. Las mayores compañías valencianas eran familiares y colectivas ${ }^{10}$. Los Loring optaron mayoritariamente por las sociedades en comandita. Tanto en Valencia como en Málaga los contratos tenían una vida muy corta, pues se actualizaban acorde a las circunstancias familiares y las comerciales. En Valencia tuvo mayor peso el sector comercial y concretamente el de productos agrícolas, como en Málaga, pero con mayor entidad de las empresas industriales.

Volviendo al reparto testamentario redactado después de la muerte del patriarca de los Loring, a Jorge Enrique, como al resto de sus hermanos menores, le correspondieron $483.281 \mathrm{r}$, como se puede observar

9. G. McDonogh, (1989), 61-89.

10. A. Pons y J. Serna (2012), 205 y 206. 
en la tabla 1. Se liquida a los hijos menores con las existencias de los almacenes y el efectivo que disponía Elijah Loring, hermano del testador y representante de dicha sociedad en Boston ${ }^{11}$. Ese será el inicio de capitalización de Jorge Enrique Loring que administrarán sus curadores hasta cumplir la edad de 25 años ${ }^{12}$.

Tabla 1. Reparto testamentario después de la muerte de Jorge Loring James

\begin{tabular}{|l|r|}
\hline Relación de bienes: & \\
Inmuebles y muebles & 1.480 .000 \\
30\% Sociedad Jorge Loring y Compañía & 4.039 .540 \\
Varios & 1.455 .017 \\
TOTAL CAUDAL & 6.974 .557 \\
Gastos funerales, notariales, caridad & -430.620 \\
TOTAL CAPITAL A REPARTIR & 6.543 .000 \\
\hline Reparto de la herencia: & \\
CAUDAL PATERNO & \\
Antes matrimonio & 3.271 .968 \\
CUERPO CAUDAL PATERNO & 400.000 \\
Legados herencia (a su mujer, suegra & 3.671 .968 \\
cuñado, capataces y empleados) & -289.000 \\
CAUDAL A REPARTIR & 3.382 .968 \\
Corresponde a cada hijo (entre 7) & 483.281 \\
CAUDAL MATERNO & 3.271 .268 \\
(María Rosario Oyarzabal) & 120.321 \\
Otros. & 3.591 .589 \\
TOTAL CAUDAL MATERNO & \\
\hline
\end{tabular}

Fuente: Elaboración propia a partir del AHPMa. Valores: en reales de vellón (r).

11. Archivo Histórico Provincial de Málaga (AHPMa), Fe pública Protocolos notariales (FPPN), Testamentos y dotes: n. $^{\circ}$ 4105, fols. 1249-1272. De este expediente se han extraído los datos de Tabla 1. Reparto testamentario después de la muerte de Jorge Loring James, 6 de julio de 1844.

12. AHPMa, FPPN, Testamentos y dotes: n. $^{\circ}$ 4105, fols. 1249-1272. De este expediente se han extraído los datos de la Tabla 1. Reparto testamentario después de la muerte de Jorge Loring James, 6 de julio de 1844. 
La sociedad de comercio Jorge Loring y Cía. la había creado su padre con el fin de dar carácter social a la anterior empresa personal. La escrituró el día 16 de agosto 1841, cuando determinó retirarse de los negocios "por razón de su avanzada edad y quebrantada salud". George Loring James optó por la solución de sociedad en comandita, actuando como socio mayoritario capitalista, dejando a su cuñado Juan Oyarzábal y al hijo mayor José Jorge la dirección de la empresa. Cuando murió, su mujer Rosario Oyarzábal, le sustituyó. En esta sociedad la principal actividad era la exportación de vinos a América ${ }^{13}$. El 15 de enero de 1848 se produjo una ampliación de capital de la Compañía. Esta fórmula se utilizó para incorporar a Jorge Enrique Loring Oyarzábal a la empresa al cumplir la mayoría de edad. Aportó al capital social de la compañía $440.000 \mathrm{r}^{14}$ para lo que empleó la herencia paterna.

El origen heredado del capital de Jorge Loring es compartido por dos de los principales banqueros catalanes: Manuel Girona y Carlos López Bru (segundo marqués de Comillas). Los otros dos, Fontanellas y los hermanos Vidal Cuadras son ejemplos de comerciantes hechos a sí mismos ${ }^{15}$. En Sevilla José María Ybarra, patriarca de los navieros, estará amparado por el capital familiar asentado en Bilbao y relacionado con la nueva siderurgia ${ }^{16}$. José Campo procedía de una rica familia comercial aragonesa, pero sus orígenes en Valencia contaron con poco capital. Dotres tuvo el apoyo de los socios catalanes y Tenor contó con la aportación importante de su familia ${ }^{17}$.

En Málaga la primera generación de la oligarquía de la Alameda, comenzó desde abajo. Manuel Agustín Heredia fue un simple dependiente de una ferretería en Vélez Málaga, George Loring James se inició como capitán de barco mercante, y los primeros Larios se establecieron en Málaga con muy pocos recursos. La segunda generación, de Tomás Heredia, Jorge Loring y Martín Larios (etiquetados por los historiadores locales como "Triángulo Financiero") partieron de una espléndida educación y herencia. Esas características de las segundas y terceras generaciones de familias industriales fue defendida por la "teoría de la tercera generación" referida a Cataluña. En las casas industriales

13. AHPMa, FPPN, Sociedades mercantiles (SM), n. ${ }^{\circ} 4.102$, fols. 876 a. y 875-879. Escritura de constitución de la sociedad Jorge Loring y Cía., 15 de enero de 1841.

14. AHPMa, FPPN, SM, n. ${ }^{\circ} 4.110$, fols. 33-36. Ampliación de capital de la sociedad Jorge Loring y Cía., 15 de enero de 1848.

15. M. Rodrigo y S. JACOBSON (2009), 47-53.

16. M. Sierra Alonso (1990 y 2009), 146 y 24.

17. A. Pons y J. Serna (2012), 250.

(C) Baetica. Estudios Historia Moderna y Contemporánea, 38, 2018, 193-225.

Facultad de Filosofía y Letras, Universidad de Málaga. Departamento de Historia Moderna y Contemporánea 
importantes, con la tercera generación se producía una grave crisis y acababa en bancarrota. El fundador o abuelo, la crea con gran esfuerzo. El padre contribuye decisivamente en su prosperidad. Por fin, los hijos que no colaboraron en el proceso, se vuelven blandos y débiles y no comprenden el valor de lo heredado, originando el final de la empresa familiar ${ }^{18}$.

En el año sesenta se disuelve Jorge Loring y Compañía; hermano y tío dejan paso a Jorge Enrique en la cabeza del negocio familiar. El final del documento de disolución se dedica a los créditos que Amalia Heredia y Rosario Oyarzábal habían concedido a la empresa. La deuda con Rosario Oyarzábal ascendía a 1.498 .790 r, pero la más significativa era la de Amalia Heredia (mujer de Jorge) que llegaba a la importante cantidad de 7.139.862 r. Jorge Loring de hecho controlaba la sociedad Jorge Loring y Cía a través de esos créditos aunque su participación era minoritaria respecto a los otros directores.

La sociedad de comercio Loring Hermanos se constituyó bajo las bases comerciales de la antigua Jorge Loring y Cía. y solo tres días después de la disolución de la misma. La sociedad se creó "en comandita", quedaba dirigida por los hermanos Jorge Enrique y Eduardo Loring (el menor de la familia), como socios capitalistas colectivos con capacidad de firma y de administración de la misma, mientras que la madre quedaba como socia comanditaria ${ }^{19}$. Los capitales aportados por los socios fueron: Jorge Enrique Loring lo hacía por 3.169.494 r, lo que suponía un 73\% del capital escriturado (4.334.838 r), esta aportación inicial a la sociedad nos define claramente quién tenía el liderazgo de la nueva empresa. La partición de beneficios será proporcional a la aportación de capital, pero hace una salvedad en Eduardo a quien además de la participación según capital se le incrementará con un diez por ciento, "en atención a su mayor trabajo que ha de prestar" 20 . Nos refleja que "el día a día" de la empresa Jorge lo hace descansar en su hermano Eduardo. Esto le permitió la intensa actividad de estos años: dedicación como diputado a Cortes, dirección y gerencia del ferrocarril a Córdoba y otras actividades societarias relacionadas con el Triángulo Financiero Malagueño.

18. G. McDonogh (1989), 88.

19. Como ya vimos sólo se hacía responsable con el capital aportado a la sociedad, y por tanto no respondía con todo su patrimonio personal, pero no podía intervenir en las decisiones de dirección de la empresa.

20. AHPMa, FPPN, SM, no 5.028, fols. 420, 422, 430a, 431 y 426-429. Carta de pago de obligaciones a D. Juan Oyarzábal y Disolución de la sociedad Jorge Loring y compañía. Escritura de constitución de la sociedad Loring Hermanos. 23 de abril de 1860. 
En resumen, Loring toma la iniciativa constituyendo la nueva sociedad familiar, dejando a un lado a los directores fundadores (su hermano mayor y tío), que tenían la mayoría de las acciones de la antigua empresa. Un caso similar lo encontramos en los tormentosos juicios de los hermanos Fontanellas. Aunque se sitúa casi cincuenta años antes y en Barcelona, Francisco Fontanellas ${ }^{21}$ logró el liderazgo de la empresa familiar teniendo al hermano menor como aliado frente al hereu o hijo mayor, Antoni, e incluso a la opinión del propio padre. Logró que Antoni quedara desahuciado y que bordeara la pobreza, lo que le proporcionó reputación de hombre implacable y vengativo ${ }^{22}$. Muy al contrario que en este caso, las posibles y evidentes desavenencias familiares que la constitución de la nueva sociedad provocaría en los Loring, no originaron juicio alguno, ni sufrió Jorge deterioro en su imagen pública.

\subsection{La dote de Amalia Heredia}

El papel de la mujer en la sociedad burguesa era la de madre y esposa, descansando en ella la responsabilidad de la casa y la educación de los hijos. Respecto a la petición de mano el patriarcado se ejercía desde la absoluta legitimidad paterna, y la autorización era obligatoria hasta alcanzar la mayoría de edad. Los hijos no la adquirían hasta los veinticinco años, pero aun cuando fueran mayores de edad, los cónyuges habrían de solicitar la anuencia del padre, por la autoridad que representaba, pero también por la amenaza de ser desheredados.

Tras el cortejo reglado, convenientemente custodiado en alamedas y salones de baile, el protocolo notarial era el paso previo a la boda. En él se establecía el contrato conyugal como si se tratara de uno mercantil, la aportación de los socios eran: la dote, las arras y los regalos. La dote era lo que el padre entregaba a su hija y esta cedía al marido. Las arras era lo que el prometido ofrecía a cambio de la dote; además, el marido solía ofrecer regalos, normalmente joyas. Estas estaban escrupulosamente valoradas en el contrato matrimonial, y normalmente durante el viaje de bodas la mujer las escogía en una joyería parisina o londinense. Lo normal era un intercambio entre iguales, por lo que la contribución de ambas partes

21. Francisco Fontanellas (1772-1851) representó la personificación de los comerciantes capitalistas barceloneses, anteriores a los bancos comerciales. Hecho a sí mismo, hizo su fortuna con el comercio con ultramar y las contratas estatales.

22. S. JACOBSON (2009), 53-78. 
habría de ser equitativa y los términos debían de negociarse ${ }^{23}$.

Amalia, futura mujer de Jorge Enrique Loring, era la cuarta hija de Manuel Agustín Heredia, por detrás de Isabel, Manuel Agustín y Tomás. Estos últimos en el momento de la muerte de su padre eran mayores de edad y por lo tanto con capacidad de percibir el resultado de la herencia. Amalia, cuando murió el padre en 1846, era aún menor y por lo tanto estaba bajo la tutela de la madre, Isabel Livermore; como se recoge en el testamento que ambos esposos legalizaron el 27 de febrero de $1846^{24}$.

La fortuna y propiedades de Manuel Agustín Heredia ya han sido estudiadas por su biógrafo ${ }^{25}$, a través del inventario post mortem que elaboraron los cuñados Miguel Bryan y José de la Cámara en el año 1847. Las propiedades eran diversas, el transporte marítimo lo realizaban mediante doce bergantines, una fragata y otras de menor eslora. Ese comercio requería almacenes para la mercancía, localizados en calle Cuarteles y en la Malagueta. Además aparecen tres fábricas de jabón en calle Salitre y otra de artículos plomíferos en Adra. Otras dos estaban en construcción: una fábrica de productos químicos y otra de hilados y tejidos (la futura Industria Malagueña). Respecto a las ferrerías La Constancia y La Concepción, al atravesar en esos momentos dificultades, había que invertir e inyectar capital.

Además incluían, acciones y mercancías de todo tipo, en conjunto estas alcanzaban un valor cercano a los once millones y medio de reales. Entre las fincas urbanas, casi todas en Málaga, destacan el pasaje de Heredia en la plaza de la Constitución (valorado en casi un millón de reales). Los deudores se extienden por Europa y América, el volumen de los créditos sobrepasaban los 19 millones de reales, lo que nos indica un negocio en plena actividad, y que el capital estaba en circulación como corresponde a un empresario de su tiempo ${ }^{26}$.

En el reparto de esos bienes en 1847, a Amalia Heredia le correspondía como legado paterno algo menos de tres millones y medio de reales, como al resto de los hermanos. En el año 1850 se hizo el reparto definitivo de la herencia del matrimonio Heredia después de la muerte de Isabel Livermore en 1848; y a los cuatro meses se casaron Jorge Loring y Amalia Heredia, iniciando un viaje de bodas, cultural y de negocios, que se prolongó hasta casi completar el año.

23. A. Pons y J. Serna (2012), 159-165.

24. AHPMa, FPPN, Testamentos y dotes (TD), n ${ }^{\circ}$ 4107, fol. 1254 v. Testamento de Agustín Heredia e Isabel Livermore, 27de febrero de 1846.

25. C. García Montoro (1978), 117-122.

26. AHPMa, FPPN, TD, n. ${ }^{\circ} 4.108$, fols. 1539-1560. Inventario de bienes según testamento de Manuel Agustín Heredia, 1847. 
La partición de los bienes de Isabel la realizaron D. José de la Cámara y D. Miguel Bryan, que cerraron los balances al 31 de diciembre de 1848 . Las partidas del Cuerpo General de Bienes (C. G. B.) son muy similares en conceptos al realizado a la muerte de D. Manuel Agustín pero alcanzando los 39.648.961 r (incluidas las legítimas paternas y maternas de los Livermore) que se dividirá en siete partes iguales según el testamento comunal. A continuación comienza la partición entre los herederos, a cantidades iguales de 5.664.137 $\mathrm{r}$ cada una. Se detallan los bienes heredados por la futura mujer de Jorge Loring en la tabla 2.

Tabla 2. Adjudicación y pago a la Sra. $D^{a}$ Amalia Heredia Livermore, en la liquidación a la muerte de Dña. Isabel Livermore

\begin{tabular}{|c|c|}
\hline $1 / 7$ parte de deudores de $1 .^{\mathrm{a}}$ clase & 1.012 .442 \\
\hline $1 / 7$ parte de deudores de $2 .{ }^{a}$ clase & 663.515 \\
\hline $1 / 7$ buques & 220.000 \\
\hline $1 / 7$ efectos plomizos & 551.715 \\
\hline $1 / 7$ clientes & 118.336 \\
\hline $1 / 7$ morosos & 737.149 \\
\hline 1/7 Fábrica San Andrés de Adra y agregados & 140.000 \\
\hline 1/7 Industria Malagueña (1,5 acción) & 297.144 \\
\hline 1/7 Fábrica Productos Químicos de Málaga & 160.000 \\
\hline 1/7 Herrería La Constancia & 1.337 .351 \\
\hline Casa Hoyo Esparteros n. ${ }^{\circ} 29$ & 97.000 \\
\hline Fábrica Jabón C/ Salitre n. ${ }^{\circ} 9$ (El Perchel) & 81.223 \\
\hline Almacenes en C/ Pescadores n. ${ }^{\circ} 8$ & 220.000 \\
\hline 1/7 parte Fábrica de curtidos de José de la Cámara & 14.285 \\
\hline Acciones Banco de S. Fernando & 13.571 \\
\hline TOTAL & 5.664 .137 \\
\hline
\end{tabular}

Fuente: Elaboración propia a partir del $\mathrm{AHPMa}^{27}$ Valores: en reales de vellón (r).

No es extraño pues, que Amalia con veinte años ( $\sin$ mayoría de edad), opte por casarse con Jorge Loring de 28 años y por lo tanto con capacidad de administrar tan suntuoso legado. Contaba con la edad, la preparación

27. AHPMa, FPPN, TD, n. ${ }^{\circ} 4.112$, fols. $1308 \mathrm{r}$ y $1332 \mathrm{r}$ a 1333 r. Liquidación y partición de bienes de la Sra. Dña. Isabel Livermore, 1850. 
universitaria y la corta experiencia de administrar (junto a hermano y tío) el negocio familiar de los Loring. Buen acuerdo societario que satisfizo a las dos partes. Ese carácter mercantil del matrimonio se podría confirmar mediante un documento previo a la ceremonia, que doy por desaparecido, y al que se refiere la escritura de dote de Amalia Heredia Livermore. A los pocos días se fueron los novios de viaje y "quedaron en poder de D. Manuel y D. Tomás Heredia todos los bienes de Amalia", como "curadores ad bona". Una vez vueltos del viaje Jorge Loring se hace cargo de los bienes de su esposa: "otorgando la correspondiente escritura para que sea carta de dote de su esposa...", sus hermanos políticos entregaron a Jorge Loring el importe de la dote, que incluye las legítimas materna y paterna y las utilidades correspondientes.

Tabla 3. Carta de dote de Amalia Heredia. Entrega a Jorge Loring

\begin{tabular}{|l|r|}
\hline 1) Dinero en efectivo o genero de comercio & 3.341 .521 \\
2) Corbeta Amalia de 229 TN & 180.000 \\
3) Recibos de efectos de morosos & 1.225 .352 \\
4) Deudores de la Cía. M. A. H. & 1.102 .618 \\
5) Parte de la Fundición de plomo de Adra & 230.000 \\
6) 2,5 acciones de Industria Malagueña & 495.240 \\
7) 7 acciones de la Herrería de Heredia. & 700.000 \\
8) Fincas & 1.400 .000 \\
9) Varios & \\
Crédito a la herrería & \\
Dividendos fábrica de productos Químicos & \\
Crédito a José de la Cámara, para limosna ... & \\
\hline
\end{tabular}

Fuente: Elaboración propia a partir AHPMa ${ }^{28}$. Valores: en reales de vellón (r).

De toda la documentación estudiada en este apartado obtenemos la aportación al matrimonio de Jorge Loring y Amalia Heredia en el acto del matrimonio, fue un año después cuando se protocolizó la dote de Amalia que incluimos en la tabla 3. En definitiva el resultado es muy similar al anunciado en la tabla 2 correspondiente sólo a la herencia paterna, ya que

28. AHPMa, FPPN, TD, no 5.002, fols. 360 an, 360 a 368rv y 358-366. Dote de D. ${ }^{a}$ Amalia Heredia contra Jorge Loring, 25 de abril 1851. 
la entidad del desequilibrio patrimonial es parecido: Loring aporta al matrimonio aproximadamente el diez por ciento que Amalia. Aun cuando el porcentaje de las herencias paternas era de un catorce por ciento, debido a que en el momento del matrimonio Rosario Oyarzábal aún vivía y por lo tanto Loring no había percibido la herencia materna, como se aprecia en la tabla 4.

Tabla 4. aportación a la Sociedad Matrimonial de Jorge Loring y Amalia Heredia

\begin{tabular}{|l|c|c|c|}
\hline \multicolumn{1}{|c|}{ CONCEPTO } & $\begin{array}{c}\text { JORGE LORING } \\
\text { OYARZÁBAL }\end{array}$ & $\begin{array}{c}\text { AMALIA } \\
\text { HEREDIA }\end{array}$ & $\begin{array}{c}\% \\
\text { Jorge / Amalia }\end{array}$ \\
\hline $\begin{array}{l}\text { Capital antes de la boda, } \\
\text { herencia paterna }\end{array}$ & 483.282 & 3.485 .266 & $14 \%$ \\
\hline Partición Isabel Livermore 1848 & & 5.664 .137 & \\
\hline Suma legítimas & 483.282 & 9.149 .403 & \\
\hline Beneficios de Jorge Loring y Cía. & 456.582 & & \\
\hline $\begin{array}{l}\text { Aportación sociedad matrimonial } \\
\text { en } 1850\end{array}$ & 939.864 & 9.947 .839 & $9,45 \%$ \\
\hline
\end{tabular}

Fuente: elaboración propia a partir de datos incluidos anteriormente del AHPMa. Valores: en reales de vellón (r).

Las "buenas familias" catalanas decimonónicas han sido estudiadas antropológicamente por $\mathrm{McDonogh}$ con detalle. Se considera que la fusión de esas familias mediante contratos matrimoniales supuso el ennoblecimiento de la riqueza, junto a la renovación de los antiguos estamentos. Defiende pues, la aristocratización de la burguesía catalana; entendiendo el término aristocracia como la que se recibe como herencia por sangre. La continuidad de la elite quedaba garantizada por la unión endogámica de esas familias, como hace la aristocracia, su estudio es idóneo para explicar las funciones de los grupos de poder. Es más, el fenómeno se repite en toda Europa.

Esa endogamia de clase origina una concentración social o al menos una acumulación de capital. En Barcelona el novio, en un noventa y ocho por ciento de los casos, solía casarse con una mujer de una misma clase social o algo superior a la suya. Teniendo en cuenta que esa decisión correspondía enteramente a los padres. La dote era una ayuda potencial para la familia del novio, y para la novia una pérdida de capital. La administra- 
ción de sus bienes pasa de estar en las manos del padre a las del marido. El promedio al que ascendían esas dotes para comerciantes e industriales, en 1858 , era de $49.420 \mathrm{r}^{29}$.

En Valencia estas se sitúan entre cien mil y el millón de reales, convirtiéndose con el tiempo en un signo de distinción social. Aunque hubo casos de desigualdad, la norma será el intercambio entre iguales, se citan, entre los primeros y más singulares, las bodas de Gaspar Dotres y Andrés Pou con las respectivas criadas $^{30}$. En Barcelona el porcentaje de matrimonios con resultados de desigualdad es tan sólo de cuatro casos de los ochocientos estudiados por McDonogh. Es también el caso de George Loring James, quien casó con Rosario Oyarzábal, sobrina de la ama de llaves. En el contrato matrimonial entre Amalia y Jorge el desequilibrio aparece invertido, siendo la dote muy superior a las arras (se multiplica por diez), justificado por el extenso patrimonio y capital que Manuel Agustín Heredia dejó a sus hijos. Lo que acentúa la singularidad de este matrimonio.

\section{PRÁCTICAS EMPRESARIALES INCONFESABLES}

Junto a las conocidas actividades empresariales de Loring, a las que ya he hecho referencia anteriormente, Loring tuvo relación con negocios que en su época ya no tenían buena reputación, lo que no quiere decir que no se practicaran dentro del entorno del empresario, e incluso alguno de ellos estaba bastante extendido, me refiero al de prestamista. El de esclavista no tanto, pero mucho más de lo que se reconocía. Es difícil evaluar el peso de esas actividades en el conjunto del negocio que generaba Loring con la documentación conocida. Aunque ninguno de los dos modificó sustancialmente su balanza financiera, ni fue predominante, nos sirve para destacar contrastes y perfilar al personaje fuera de la imagen pública.

\subsection{Comerciante capitalista o prestamista}

El préstamo empresarial, antes de la consolidación del negocio bancario, estaba vinculado a las casas de comercio familiar que proliferaron en la Málaga de final del XVIII y durante el XIX. ¿Se puede considerar prestamistas a los firmantes de esos contratos hipotecarios? Una de ellas fue Jorge Loring y Cía., de la que ya he hablado para explicar el inicio de

29. G. McDonogh (1989), 143-211.

30. A. Pons y J. Serna (2012), 164.

(C) Baetica. Estudios Historia Moderna y Contemporánea, 38, 2018, 193-225. Facultad de Filosofía y Letras, Universidad de Málaga. Departamento de Historia Moderna y Contemporánea 
la capitalización del empresario malagueño. En el año 1841 George Loring James se había retirado del negocio mercantil, descansaba la empresa en Juan Oyarzábal. Valgan como ejemplos cuatro documentos que hablan de esa actividad. Uno de ellos se efectuó contra Juan Bautista Jáudenes, no es un préstamo, pero tiene un carácter evidentemente bancario al actuar como intermediario en el pago de una herencia de un tal Stauhgton que murió en Boston y había que abonárselo a la mujer e hijos, que vivían en Málaga. En otro, Rodríguez había solicitado un crédito de 11.000 $r$ a la firma de los Loring, lo que nos puede indicar el origen de esta operación. Otro, afecta a Rafael y Josefa Serra, se refiere a la operación hipotecaria realizada por el padre, en la que se entregaron sus títulos de propiedad de la finca a cambio de dinero. En el documento se hace constar que no saben escribir, por lo que firma un testigo por ellos. Otra operación crediticia de garantía hipotecaria la realiza con Rafael María de Lara, asciende a la cantidad de $132.000 \mathrm{r}$ "para atender las labores de sus viñas", el pago se realizará mediante pasas "el próximo año" ${ }^{11}$. Este es el tipo documento más habitual, excepción hecha del importe que es más alto de lo normal.

Muerto Jorge Loring James, la empresa Jorge Loring y Cía. continúa con la actividad de préstamo hipotecario, por ello detectamos un crédito contra Francisco de las Navas Mancilla de Cómpeta, efectuada por el mayor de los Loring; el importe ascendió a 41.000 rv. De los mismos rasgos pero de menor importe $(5.535 \mathrm{rv})$ fue la realizada por Juan Aranda en 1837. La dificultad en pagar que vislumbramos por los acreedores, queda confirmada por otro documento, igual al anterior, solicitado por los herederos de José de Gálvez. Este pidió a la firma en 1842 un crédito de $51.300 \mathrm{r}$ con vencimiento en el mismo año, pero sólo pagó $4.400 \mathrm{r}$, por lo que se hizo otra escritura en el año 1843 hipotecando la hacienda Santillán en Vélez. Para recibir la carta de pago y liberar la finca hipotecada, los herederos han de pagar en 1851 lo no abonado por el padre ${ }^{32}$.

Jorge Loring Oyarzábal una vez se hizo con las riendas del negocio familiar en los años sesenta, y constituida la nueva razón social como Loring Hermanos continúa con la práctica crediticia. Así lo certifica la obligación firmada por él en 1860 en contra de Francisco Rosado

31. AHPMa, FPPN, SM, n. ${ }^{\circ} 4102$, fols. 1214,1182 y 1227. Carta de pago y obligación de Jorge Loring y Cía. contra Juan Bautista Jáudenes y Rafael María de Lara, 1841.

32. AHPMa, FPPN, SM, n. ${ }^{\circ} 4107,4529,5002$, fols. 886, 195 y 844. Carta de pago de D. José de Gálvez contra Jorge Loring y Cía., 1851. 
por importe de $40.000 \mathrm{r}$, a un interés anual del $6 \%$ anual con plazo de noventa días. La novedad es que las propiedades que garantizaron la operación fueron urbanas, una casa en calle Pescadores y otra en calle Esparteros. Otra obligación la firmó contra Francisco González Bonilla, la deuda procedía de 1853, por un importe de 45.000 rv, hipotecando su finca de viñas en Coín. En 1864 "Loring Hermanos" es autorizada a cobrar las deudas de la anterior empresa familiar, por vía de apremio, por ello solicita la devolución del crédito que ascendía a $46.153 \mathrm{r}$ incluidos intereses. "Debido a su avanzada edad" opta por una quita, quedando la deuda en $35.000 \mathrm{rv}$. a pagar en 6 años en metálico, a razón de $2.000 \mathrm{r}$ anuales, ofreciendo como garantía dos casas en Coín. Otra operación de crédito, esta vez personal, la realizó contra Juan Rodríguez Sánchez, el valor era de $200.000 \mathrm{rv}$, y en el documento se hipotecaba el cortijo Alecey en Casabermeja. De iguales características lo fue otra contra Antonio Madrid Postigo con un importe de $60.000 \mathrm{r}$, a pagar tres años más tarde, la peculiaridad fue que se indicaba que "no media premio o interés" y la garantía fuera un cortijo en Benagalbón que se valoraba en $100.000 \mathrm{r}^{33}$.

En la tabla 5 se refleja una muestra más amplia que las anteriormente relacionadas de operaciones de créditos hipotecarios en los que intervino Jorge Loring Oyarzábal. La media del importe de estos, eliminando el de mayor valor, alcanza un importe de 38.264 r; lo que demuestra la humildad de los acreedores. Ya hemos visto que algunos no saben ni leer ni escribir, pues los beneficiados del préstamo pertenecían a un ambiente campesino, lo que justifica que la devolución de los préstamos sea en especie al finalizar la cosecha ${ }^{34}$.

33. AHPMa, FPPN, SM, n. ${ }^{\circ}$ 4629, 4641, 4638 y 4637, fols. 11, 876, 2325 y 981. Obligación de D. Jorge Loring contra Francisco Rosado, Francisco González Bonilla, Juan Rodríguez Sánchez y Antonio Madrid Postigo, 1860, 1864, 1864 y 1865.

34. M. V. Campos Rojas (1986), 116-136. 
TABLA 6. ESCRITURAS COMO PRESTAMISTA DE JORGE LORING

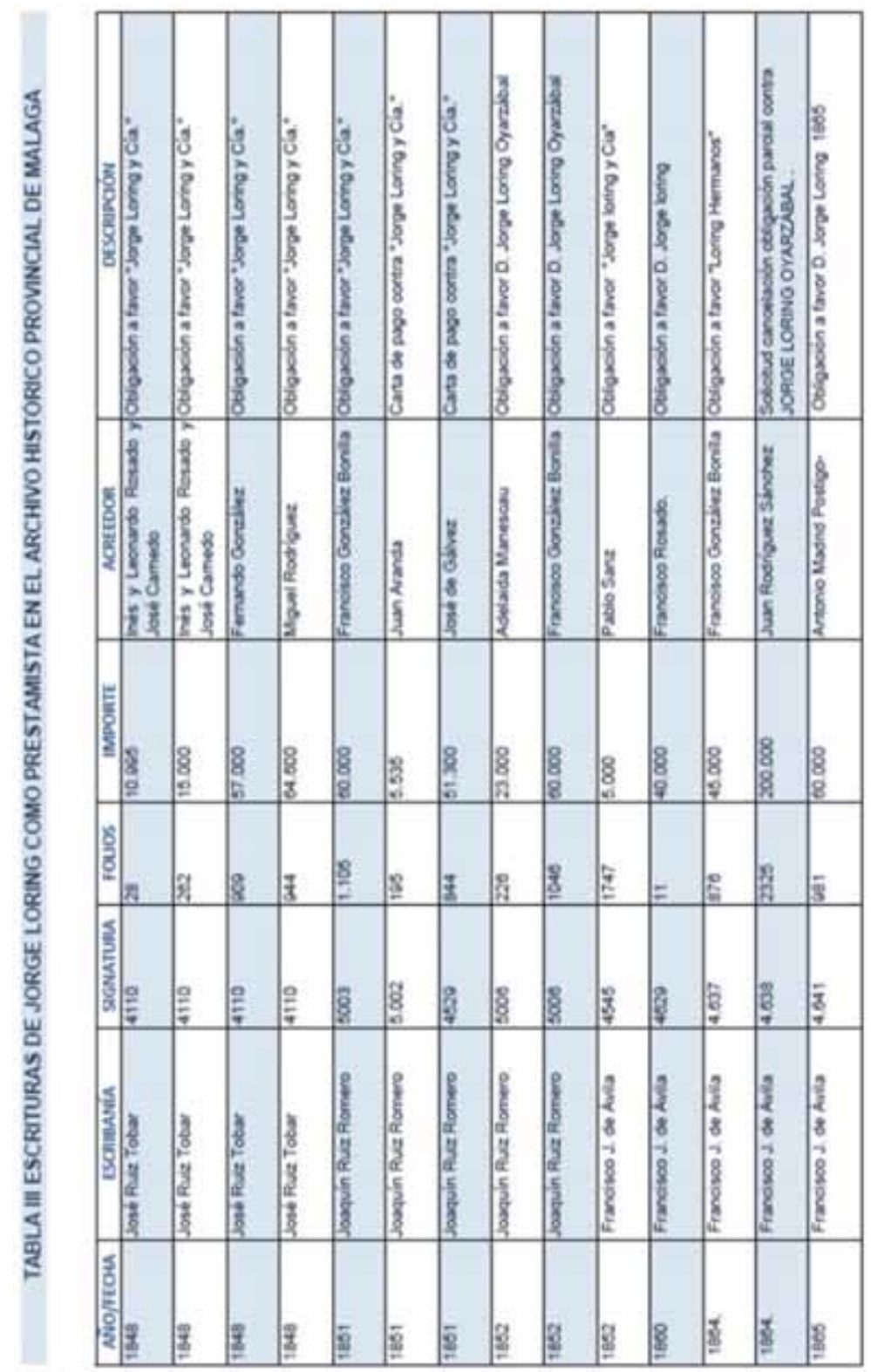

Fuente: Elaboración propia a partir de las referencias del AHPMa, estudiadas por M. V. CAmpos RoJas (1986). 
La generalidad de las propiedades que avalaban el crédito eran fincas de vides; Jorge Loring aunque diversificó los negocios con Loring Hermanos, sabemos que continúa con los créditos hipotecarios mucho más allá de la mitad de los años sesenta. El control de los créditos hipotecarios facilitó su cacicato en ese ambiente vitícola propio de la Axarquía malagueña y en la zona de influencia agrícola de Málaga capital. En los pagos de Arroyo de la Miel se conoce que tuvo tierras en propiedad como consecuencia del impago de uno de esos préstamos.

Durante gran parte del periodo en el que actuó como prestamista, Jorge Loring tuvo mucho que ver con el Banco de Málaga, siendo uno de los fundadores. Este fue creado en el Bienio Progresista al amparo de la Ley de Bancos de Emisión de 28 de enero de 1856. A solicitud de la Junta de Comercio Jorge Loring fue el encargado de promover su fundación ante el Gobierno de Madrid, se creó para ello una Junta Provisional encabezada por Loring y Joaquín Ferrer y Escobar quienes redactaron los Estatutos, estaban también en la junta Martín Larios y Martín Heredia.

El 1 de noviembre de ese mismo año, las puertas del banco quedaron abiertas al público, se ocupará del descuento de letras, pagarés y efectos, hipotecas no inmobiliarias, adelantos por joyas, cuentas corrientes y administración de acciones en Málaga y provincias; y sobre todo, a la emisión de billetes de 100 a $4.000 \mathrm{r}^{35}$. En la Memoria del 3 de abril de 1858, aparecen Martín Larios y Joaquín Ferrer en la dirección de la sociedad, actuando de conciliarios Jorge Loring y Tomás Heredia ${ }^{36}$.

El profesor Morilla plantea que fue una institución controlada por la elite económica de Málaga ${ }^{37}$, defiende que su actuación fue contradictoria pues aunque se fundamentaba en los ahorros de los malagueños, los préstamos y descuentos iban a parar a entidades ajenas a la provincia, lo que tuvo como consecuencia la descapitalización de la economía local. Concreta entre las causas de la quiebra (1874), el descuento de letras a la compañía jerezana Pemartín, y las operaciones de crédito en Asturias e Inglaterra, todo ello en plena crisis financiera que llevó a la desaparición de gran parte de los bancos locales absorbidos por el Banco de España que monopolizó la emisión de papel moneda.

Jorge Loring siguió la tradición de prestamista de su padre y a su vez se sumó a la modernidad siendo uno de los fundadores del Banco de

35. El Avisador Malagueño, 05-07-1856.

36. M. Morales (1983), 56.

37. J. Morilla Critz (1975), 24.

(C) Baetica. Estudios Historia Moderna y Contemporánea, 38, 2018, 193-225. Facultad de Filosofia y Letras, Universidad de Málaga. Departamento de Historia Moderna y Contemporánea 
Málaga. Para despejar esa aparente contradicción y la duda que planteo en el título de este epígrafe, comparo la experiencia malagueña con la barcelonesa y valenciana, también, aunque con menos similitud, con asturianos y sevillanos. Jacobson ha estudiado el origen del banquero decimonónico en la singular personalidad de Francisco Fontanellas con una metodología propia de la Historia Cultural, para ello se ha basado en la metodología y terminología empleada por Martin Wiener para Gran Bretaña.

Sitúa el origen de la banca comercial inglesa en los banqueros que se dedicaron al comercio colonial y los "comerciantes banqueros" de la gentry rural. Los empresarios se vieron seducidos por los lujos, encantos y el poder político de la gentry. En los años cuarenta, la revolución liberal había generado la liberalización de la propiedad; todo ello originó un aumento de las necesidades financieras que no pudieron ser cubiertas por los bancos, los comerciantes y los banqueros privados suplieron esa carencia. También acuñó el término de "capitalismo de caballeros" que se refería a un fenómeno de carácter cultural, no económico, por el que Inglaterra perdió la preminencia económica a final del siglo XIX. Estos "caballeros capitalistas" eran fríos y calculadores empresarios de día, pero no hablaban de dinero en la vida pública sino de valores aristocráticos como el honor, la justicia, la civilización y la filantropía. Así se originó la aristocratización de la burguesía y la decadencia económica en Gran Bretaña.

En Cataluña los "comerciantes banqueros", surgieron con los primeros empresarios industriales, fueron hombres hechos a sí mismos y sin esmerada educación, configurando un personaje característico de la primera mitad del Ochocientos, anterior a la consolidación del sistema bancario, y por lo tanto a los bancos comerciales. Conformaron lo que se ha venido en llamar "el capitalismo romántico", ellos se veían a sí mismos como luchadores románticos frente a la competencia y a la adversidad de la guerra y las revoluciones; sobreviviendo gracias a su voluntad, perspicacia, relaciones y buena fortuna. A lo largo del siglo se transformaron en "caballeros capitalistas".

Los "comerciantes- banqueros" catalanes se enriquecieron con el comercio de ultramar y las contratas estatales, tuvieron la máxima representación en Francisco Fontanellas. La segunda generación la personalizó Manuel Girona, fundador del Banco de Barcelona, representación de la banca comercial moderna. Estos bancos se quedaron con el negocio del préstamo, avales y aseguradoras de sus antecesores. Se sitúa en Cataluña, en la década de los sesenta, cuando aquellos superaron a los "comerciantes banqueros" 38 .

38. S. JACOBSON (2009), 53-56,

(C) Baetica. Estudios Historia Moderna y Contemporánea, 38, 2018, 193-225.

Facultad de Filosofía y Letras, Universidad de Málaga. Departamento de Historia Moderna y Contemporánea 
Esa misma aplicación de la teoría de Martin Wiener podría hacerse con las familias de la oligarquía malagueña en su primera y segunda generación, ya indicadas anteriormente. Así Jorge Loring James y Manuel Agustín Heredia (primera generación) pudieran ser un ejemplo de "capitalismo romántico", actuando como "comerciantes banqueros". Jorge Loring y Tomás Heredia (segunda generación) continuaron con la práctica hipotecaria, pero se acercaron a las características del "caballero capitalista". Sabemos de sus respectivos títulos de nobleza, actividades filantrópicas, la condición de bibliófilos, las haciendas lujosas y próximas a las afueras de Málaga, las aspiraciones políticas y de sus cortesanas fiestas. Estas características los aproximan al ideal cultural aristocrático que los llevarían a la decadencia familiar, según la interpretación de la historiografía inglesa.

En Valencia había en 1864 tan sólo seis bancos, dos de corta vida, otros dos eran sucursales y los que quedan se dedicaron a dar crédito al ferrocarril y el puerto. Las necesidades de metálico las cubrían las empresas dedicadas al comercio ultramarino, actuando como bancos particulares, como tenían corresponsales en todo el mundo, ejercían de bancos para entidades de otras plazas. Thomas Trevor por ejemplo, recibió mercancías destinadas a otras compañías para que pudieran pagar en destino ${ }^{39}$. Pero los casos más similares a los estudiados de los Loring son aquellos que proceden del adelanto de capital a cultivadores. No me resisto a transcribir un párrafo de los profesores Pons y Serna referido al préstamo privado en Valencia, aplicable en toda su extensión a los malagueños:

otro mecanismo que suele ser habitual entre burgueses es el de adelantar capital a cultivadores, a cambio de la cosecha [...] aunque figure como un préstamo - generalmente, sin interés-, aquello que pretenden es asegurarse de antemano la mercancía con la que habitualmente comercian [...] este es el caso que la familia Trénor realiza a cambio de la cosecha de la pasa ${ }^{40}$.

En Asturias una de las causas de la enorme emigración fue la falta de disponibilidad de recursos ajenos por parte de los empresarios, pequeñas sociedades familiares de crédito cubrían esas necesidades. Desde 1864 funcionó el Banco de Oviedo asociado a capitalistas vascos, que a la postre se convirtió en sucursal del Banco de España. El sistema financiero se

39. A. Pons y J. Serna (2012), 230.

40. A. Pons y J. Serna (1992), 312.

(C) Baetica. Estudios Historia Moderna y Contemporánea, 38, 2018, 193-225. Facultad de Filosofia y Letras, Universidad de Málaga. Departamento de Historia Moderna y Contemporánea 
completaba con prestamistas y usureros que proliferaban por los pueblos agrícolas $^{41}$. En Sevilla los Ybarra ejercieron también el crédito, utilizándolo como fórmula de patronazgo político a través del préstamo como favor a cambio del voto ${ }^{42}$.

\section{2. ¿Un esclavista vergonzoso?}

A comienzos del XIX comenzó a desaparecer la esclavitud en España a causa de la quiebra del absolutismo, el rechazo social y la formación del mercado asalariado. En 1837 las Cortes prohibieron la esclavitud en la Península, las islas Baleares y Canarias, pero no en el Caribe ${ }^{43}$. Don Pedro Blanco comerció durante el primer tercio del siglo XIX con Monrovia (Liberia), fue uno de los traficantes de esclavos africanos más importantes europeos, y era malagueño ${ }^{44}$.

La historiografía malagueña que ha tratado con frecuencia aspectos puramente económicos o comerciales del emprendimiento en los siglos XVIII y XIX, no habla de la esclavitud, quizá porque "en los últimos tiempos no resultaba demasiado honorable alardear de poseer esclavos" ${ }^{\prime 4}$. Si el insigne negrero de fama internacional no ha tenido el lugar que le debió corresponder en el pedestal de personajes ilustres malagueños, no debemos de extrañarnos que la dedicación al tráfico de asiáticos de una distinguida empresa malagueña haya quedado tan solo insinuada ${ }^{46}$.

41. F. ERICE (1995), 197.

42. M. Sierra Alonso (1990), 28.

43. J. M. López García, (2016), 34.

44. Pedro Blanco. Malagueño, nació el 30/07/1793, estudió en el Colegio de San Telmo, las prácticas de navegación le llevaron a La Habana. Desde allí viajó a Europa y recaló en la capital liberiana como capitán de un barco negrero (el bergantín Segundo Campeador) en 1823. Al año siguiente lo compra, estableciendo sus almacenes de esclavos en la desembocadura del río Gallinas (actual Kerafe a 100 millas de Monrovia). Las fragatas británicas ejercían de policía controlando el tráfico prohibido, esto le obligó a una organización que se hizo cada vez más compleja, contando con 10 barracones donde se hacinaban más de mil esclavos negros. En 1839 se retiró del negocio negrero, con una fortuna que se acercaba al millón de dólares. En 1841 en La Habana es acusado por su mujer de homosexualidad en su petición de divorcio, por lo que huyó hacia Europa. En 1842 vuelve a Málaga, es nombrado en 1843 intendente de Marina y se le propone la colonización de Fernando Po y Annobón. Blanco se piensa que murió en Barcelona entre 1854 y 1856. M. Burgos Madroñero (1989), 36-44.

45. E. DEL Pino, (1976), 61.

46. R. Mesa (1967), 75-109. 
A finales de los cincuenta, cuando ocurrieron estos hechos, los moderados empezaron a decaer y el espacio fue ocupado por la Unión Liberal del general Leopoldo O'Donnell. Durante el Bienio Progresista (1854-1856) se creó esa formación, era un nuevo partido político, donde confluyeron viejos progresistas y nuevos moderados. En una última etapa isabelina se alternaron unionistas y moderados, lo que llevó a O'Donnell al llamado Gobierno Largo de la Unión Liberal" (1858-1863) ${ }^{47}$. Durante ese tiempo se llevó a cabo una política exterior colonialista, dependiente de Francia e Inglaterra: intervención en México y en la Conchinchina, esta última con objetivos esclavistas. La Unión Liberal se caracterizó por el eclecticismo de sus hombres e ideas, tildándose de oportunista porque carecía de una política fija, se construyó alrededor de la figura de O'Donnell y se deshizo con su muerte.

El esclavismo español, relacionado fundamentalmente con Cuba y Puerto Rico, se verá protegido por "la estabilidad del mercado colonial que dependía de los beneficios agrarios e industriales peninsulares, además de los estrictamente negreros" ${ }^{\prime 4}$. En Cuba se produce la mayor de las paradojas: siendo colonia de un país al que la historiografía discute su "revolución industrial decimonónica", a la isla colonizada se le reconoce con unanimidad. Aunque se mantiene el sistema de producción esclavista, fue la colonia más desarrollada del siglo XIX, el único territorio del mundo, excluido Estados Unidos, que dispone de una línea regular de barcos de vapor, la que une La Habana-Matanzas. La línea ferroviaria La Habana-Güines se inaugura once años antes que la primera en la Península. En 1820 se comienza a sustituir los animales de los trapiches por máquinas a vapor.

Todo ello en un contexto en el que el esclavismo está en retroceso en el continente, siendo sólo acompañada por Estados Unidos y Brasil. La otra contradicción a destacar es que esas mismas innovaciones tecnológicas son las que incrementan la capacidad de producción de azúcar y con ello la mayor necesidad de mano de obra esclava en las plantaciones. Los esclavistas que perpetuaron esa situación lo hicieron a costa de sus aspiraciones burguesas, que fracasaron por no disponer del capital necesario para completar la mecanización necesaria para la total industrialización de la recolección de la caña, lo que les hubiera permitido prescindir de los esclavos $^{49}$.

47. N. Durán de la Rúa (1979), 71.

48. J. A. Piqueras Arenas (1992), 27.

49. J. A. Piqueras Arenas y E. Sebastiá Domingo (1991), 239-299.

(C) Baetica. Estudios Historia Moderna y Contemporánea, 38, 2018, 193-225. Facultad de Filosofía y Letras, Universidad de Málaga. Departamento de Historia Moderna y Contemporánea 
En 1854 el general De la Concha vuelve a Cuba, permanecerá cinco años gobernándola; al final de ese periodo, la Unión Liberal (UL) se puso al frente de la protección de los intereses esclavistas, ya que "Leopoldo O'Donnell era viejo colaborador de los traficantes de esclavos", que le financiaron sus veleidades colonialistas. Con el mandato De la Concha, en 1855, se descargaron en el puerto de la Habana 1.800 esclavos negros, llegando a 160.000 en 1866, de ellos más 70.000 culíes $^{50}$. Esta enorme migración forzada se produjo durante la guerra comercial que los ingleses declararon el tráfico de esclavos negros.

El Partido Español de La Habana encontró la solución en la importación de chinos, gracias a las facilidades iniciales que el Gobierno puso para la contratación: "En él tomaron parte los mismos hombres que se dedicaban al tráfico de negros, aunque también participaron casas comerciales peninsulares cuya relación con la trata todavía no ha sido esclarecida, es el caso de la malagueña Loring y Cía" ${ }^{1}$. La experiencia colonial británica en la India vendría a descubrir un filón humano inagotable, el que pondría fin al problema creado por el abolicionismo. La raza amarilla, sería el nuevo almacén aprovisionador de hombres para las colonias, en América y en Oceanía.

Los vaivenes legislativos españoles entre un abolicionismo de excepciones y una realidad de hechos consumados permitieron a los propietarios la adquisición de económicos trabajadores chinos, estimándose la población de culíes en Cuba en cien mil. En 1859 se denunciaba la mala práctica de los traficantes españoles que repatriaban chinos menores de edad, causa por la que el gobierno decide suspender las contrataciones previamente acordadas con nuestro Gobierno.

En la propia legislación española se descubre la presión por mantener el tráfico de colonos. Así en el Reglamento de 1854 en su artículo 19 expresaba que "los colonos se entiende que renuncian al ejercicio de todos los derechos civiles", aunque admite que pueden redimirse, pero de hecho lo imposibilita al exigirles la devolución del mayor valor adquirido por el culí, convenientemente peritado, quedando claro que el eufemismo de colonos camufla su condición real de esclavos. Estos son acusados además de sodomía cuando los traficantes, para evitarse el transporte llevaban mujeres

50. Sirviente indígena de la India, China y otros países orientales. (Moliner, María: Diccionario del uso del español, RBA, Madrid, 2008).

51. J. A. Piqueras Arenas (1992), 284-286. En esta última cita aparece la referencia a una operación esclavista de Loring. 
en proporciones ridículas, como veremos en el caso de Loring lo hacía en fracción de una por trescientos cincuenta y un chinos ${ }^{52}$.

A finales de los años cincuenta, Loring recorría con frecuencia en diligencia el tortuoso camino que unía Málaga con la capital del Reino, con el objeto de asistir a los plenos del Congreso del que era diputado ${ }^{53}$. Por esas fechas, a través de una carta, hacía confidencia a un amigo de la desastrosa opinión que le merecían los compañeros de escaño ${ }^{54}$. Es indudable que tanto esfuerzo debía de ir acompañado de otras compensaciones. La implicación política con la Unión Liberal, donde ya destacaba su antiguo protegido Cánovas, le supuso prebendas en el campo empresarial. Entre otras ventajas le permitía estar informado de primera mano de la situación de sus intereses ferroviarios como adjudicatario del ferrocarril Córdoba a Málaga; y otras oportunidades de negocio que gracias al escaño le situaba en posición privilegiada.

Durante ese periodo Loring constituyó un caso más de la íntima relación entre poder político y poder económico y conoció de primera mano el apoyo de la Unión Liberal al mantenimiento de la esclavitud en Cuba. También está fechado en el año 1859 el documento de la imagen 3, que confirma la participación de Jorge Loring en el tráfico de esclavos. En su primera página se indica el objeto del escrito del cónsul en Emuy al Primer Secretario de Estado y del Despacho: "comunicación relativa a la salida de la fragata española Gravina con cargamento de colonos chinos para la Habana". En la comunicación propiamente dicha se concreta que salió de dicho puerto el 25 de junio de 1859, llevando 351 chinos y una china. Eran contratados por los señores Orbeta y Cía., del comercio de Manila, en nombre de Manuel Ruiz del Castillo, apoderado de los señores Jorge Loring y Cía., del comercio de Málaga ${ }^{55}$.

52 R. Mesa (1967), 170, 181-185.

53 Aún faltaban más de cinco años para unir mediante ferrocarril Córdoba y Málaga, y poder llegar poco después a Madrid con el mismo tren.

54 Documentación particular de Jorge Benthem y Olga Mendoza. Carta de Jorge Loring a Joaquín Ferrer, 2 de febrero de 1859, Málaga.

55 Archivo Histórico Nacional (AHN), Ministerio de Asuntos Exteriores, legajo H: 2361/1848$1860, \mathrm{n}^{\circ} 12$, fols. 1-3, Comunicación relativa a la salida de la fragata española Gravina con cargamento de colonos chinos para la Habana, 2 de agosto de 1859. 


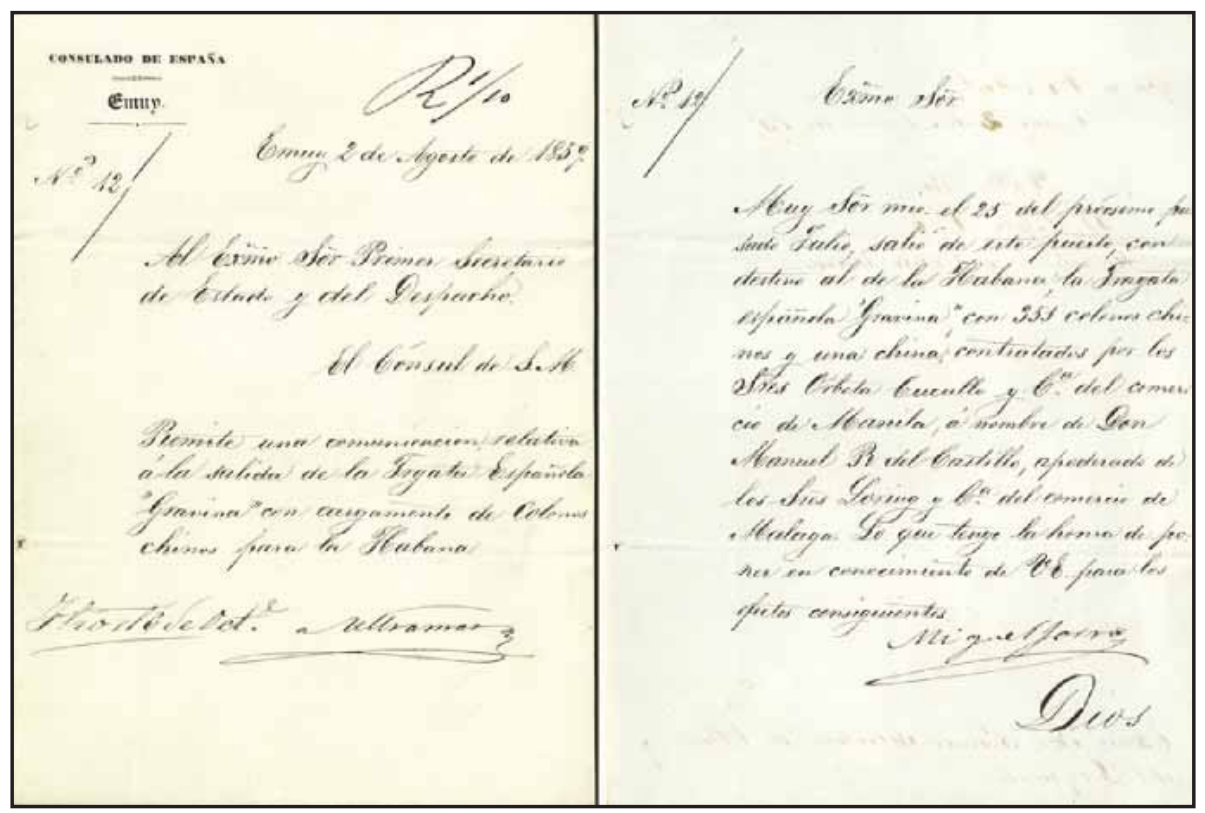

Imagen 3. Comunicación de salida de la Gravina contratada por los Sres. Loring, con cargamento de colonos chinos para la Habana, AHN.

Ese mismo legajo contiene la correspondencia cruzada entre el cónsul español en Emuy (Sr. Jorro) y su colega el vicecónsul de Inglaterra (Mr. Morrison) por causa de la Gravina. El motivo era elevar a Madrid la información de la disputa entre ambos cónsules que había generado un incidente diplomático entre ambos países, gracias a lo cual conocemos más detalles del flete. El transporte de los emigrantes sufrió grandes alteraciones por el trato vejatorio recibido por el pasaje en el momento del embarque y durante la travesía. Contra las acusaciones inglesas de ataque a los derechos humanos, Jorro eleva el tono de la disputa acusando de "manejos del protestantismo", llamando a los ingleses "misioneros protestantes" y al cónsul inglés prepotente.

Ante la protesta del cónsul británico, el de España en Amoy replicó (sin desmentir las acusaciones de su colega británico) recordándole las violaciones infringidas por los ingleses a las reglas que prohibían el tráfico de opio. Traslada el maltrato a los chinos (por lo que lo admite) a "los corredores chinos" con abusos que "rechaza la moral y la justicia". Contiene también un escrito de apercibimiento del Cónsul General en China a Jorro transmitiendo la preocupación de Isabel II por "escritos 
tan acalorados", lo que indica la transcendencia que había alcanzado el incidente ${ }^{56}$.

Algunos destacados empresarios de Barcelona y Asturias recibieron los beneficios del tráfico de esclavos. El lobby cubano-español tuvo gran influencia en las Cortes españolas que presionaron por mantener una legislación permisiva con el esclavismo en la isla. Contó este con una amplia representación catalana, de los cuatro banqueros emblemáticos de esa región, dos tuvieron el origen de la capitalización en Cuba y estuvieron muy vinculados con la trata.

La familia Vidal Cuadras, inició su riqueza en Santiago de Cuba, a la vez que destacaron en el préstamo con interés, poseyeron varias fincas con esclavos. Cuando los hermanos Manuel, Alejo y Antonio se trasladaron a Barcelona a mediados de siglo, fundaron la Banca Vidal Cuadras que continuó con el negocio de consignatarios y navieros con $\mathrm{Cuba}^{57}$.

Antonio López, primer marqués de Comillas, emigró a Cuba actuando en la intermediación de esclavos, gracias a una ventajosa boda pudo fundar una armadora dedicada a unir Guantánamo con Santiago, para satisfacer el tráfico ilegal de esclavos en el Oriente cubano. Con ese capital pudo crear la naviera Antonio López y Cía., que unía mediante línea regular la Península con las Antillas y el Crédito Mercantil, banco comercial de gran peso en Barcelona $^{58}$. En Asturias la prensa habla de colonos asturianos contratados por el Círculo de Hacendados sobre los que se ejercía una esclavitud más terrible que el de los negreros. Aunque no se conoce ningún hacendado asturiano con esclavos en Cuba, se sabe que algunos asturianos se dedicaron a este tráfico. Se considera que Ramón Argüelles Alonso (marqués de Argüelles) fue el mayor negrero de la época ${ }^{59}$.

\section{CONCLUSIONES}

Jorge Loring compartió la universalidad de la norma burguesa: justicia de mérito, vida metódica y trabajo regular, participó de ellas con dedicación y abnegación. Aunque estaba convencido del cumplimiento estricto

56. AHN, Ministerio de Asuntos Exteriores, legajo H: 2361/1848-1860, n. ${ }^{\circ} 65$ fols. 4 a 15, 2 de agosto de 1859. Correspondencia cruzada entre el cónsul español en Amoy y el vicecónsul de Inglaterra, remitido por el cónsul general de España en Macao a causa de la Gravina.

57. M. Rodrigo y Alharilla (2009), 99-119.

58. E. FAes Díaz (2009), 121-137.

59. F. ERice (1995), 112.

(C) Baetica. Estudios Historia Moderna y Contemporánea, 38, 2018, 193-225. Facultad de Filosofia y Letras, Universidad de Málaga. Departamento de Historia Moderna y Contemporánea 
de la primera, no dudó en utilizar la herencia paterna para participar en la sociedad familiar, en usar la boda para capitalizarse y controlar Jorge Loring y Cia. gracias a la dote de Amalia Heredia, en emplear el crédito a los proveedores para mantener el patronazgo político y participar en el transporte y tráfico de esclavos en contra de la moral católica. Frente a los evanescentes ideales liberales, en Loring se impone el pragmatismo y sentido utilitario burgués.

Gracias a su matrimonio, Jorge Loring pasó a administrar la herencia de su mujer, la desproporcionada diferencia de la dote respecto a las arras; y las repercusiones económicas, políticas y sociales de su matrimonio no se aprecian en los casos de Valencia. El "matrimonio entre iguales" y el equilibrio económico requerido por el contrato matrimonial era característico de la segunda generación de las buenas familias barcelonesas. Hemos visto como la casuística de los banqueros catalanes equilibra entre aquellos "hechos a sí mismos" y los que su capitalización les viene por herencia. Nada que ver con los casi diez millones de reales de la dote disfrutada por el empresario malagueño. La singularidad de Loring respecto a los burgueses valencianos y catalanes consiste en que su capitalización inicial procede fundamentalmente de su dote, no de la herencia familiar y de su esfuerzo.

Jorge Loring no fue un "prestamista profesional" como nos preguntábamos al comienzo del epígrafe correspondiente, sino un "comerciante banquero", una figura contemplada y estudiada por la historiografía inglesa. El comerciante aseguraba la materia prima para exportar y el mantenimiento de los precios, gracias al control sobre los agricultores generado por el crédito hipotecario. Así lo hicieron los comerciantes de productos vitícolas malagueños, pero también lo hemos visto reflejado en los valencianos con sorprendente igualdad en motivaciones y procedimientos. Su papel se fue diluyendo pero se mantuvo durante la Restauración como un método más de control clientelar dentro del sistema político de patrono-cliente. Loring continuó la práctica crediticio-comercial del padre, constituyendo otra contradicción: que siendo un liberal conservador convencido de las ventajas "del progreso", continuara con esa actividad mucho después de intervenir decisivamente en la fundación del Banco de Málaga. Esa práctica le permitió mantener su clientela, lo que posibilitó su ascensión y consolidación política, como hicieron los Ybarra en Sevilla con el Partido Conservador.

Los Heredia cumplieron la norma catalana de la "tercera generación", considerándose la causa de su decadencia su aristocratización, iniciada 
en la segunda, y culminada en la tercera generación despreocupada, dilapidadora y poco luchadora que despilfarra la fortuna familiar. Esta es una posible futura línea de investigación: los burgueses malagueños del Ochocientos que cumplen características culturales establecidas para la burguesía inglesa, con sus particularidades, en muchos casos similares a las de catalanes y valencianos.

El pragmatismo de la Unión Liberal a la que perteneció, tan vinculada al lobby cubano, le llevó a turbios negocios desde la delegación filipina con chinos por mercancía. Por estas fechas, hemos visto cómo Jorge Loring ya controlaba la empresa familiar Jorge Loring y Cía., y es imposible creer que desconociera esa práctica tan lucrativa de su negocio. Ramón Argüelles Alonso y Antonio López adquirieron títulos de nobleza y gozaron de gran prestigio, a pesar de que tuvieron una intervención intensa en el tráfico de esclavos.

El lobby cubano compuesto principalmente por catalanes y asturianos presionó activamente en el Congreso para defender esa actividad. El tráfico de esclavos fue una práctica admitida, circunscrita a Cuba y Puerto Rico y justificada por la viabilidad económica de la colonia, pero la verdadera causa del mantenimiento de la esclavitud estuvo en la falta de capital de los propietarios de las plantaciones, incapaces de completar la mecanización de los campos de caña. No he logrado encontrar otro documento que hiciera mención a la actuación de la empresa de Loring en el tráfico de esclavos, pero considerando que mantenía una delegación en Filipinas, el largo flete hasta Cuba justificaba el retorno con otra mercancía autóctona. El incidente diplomático de la Gravina posibilitó una documentación que normalmente se ocultaba ya que el tráfico de esclavos estaba mal visto.

Las actividades inconfesables y el origen de su capitalización hemos visto como no les eran ajenas a los burgueses de otras capitales españolas. La singularidad de Loring habría que buscarla en su capacidad estratégica y de preparación técnica que le permitió aunar voluntades en proyectos como el del ferrocarril a Málaga y la unificación de líneas en Andaluces, el Banco de Málaga y el control de las minas carboníferas del Guadiato. Para ello aglomeró a los Heredia y los Larios, a pesar de las diferencias políticas y personales que conocemos con estos últimos. Pero es en la aportación al patrimonio cultural donde Loring haya contribuido más a la Málaga actual concretada en el Jardín Botánico de La Concepción y a los monumentos arqueológicos concentrados en el Museo de la Aduana y en el Arqueológico Nacional. 


\section{BIBLIOGRAFÍA}

Burgos Madroñero, Manuel (1989), “De negrero a intendente de la marina española: Pedro Blanco", Jábega, 66, Málaga, pp. 36-44.

Campos Rojas, María Victoria (2006), Semblanza biográfica de Jorge Enrique Loring Oyarzabal. Aula de Dirección Estratégica, Málaga.

- (1987) Actividades mercantiles de la familia Loring, Universidad, Málaga.

DAUMARD, Adelaine (dir.) (1973), Les fortunes francaises au XIXe siècle. École Practique des Hautes Études and Mouton, París.

Del Pino, Enrique (1976),'La esclavitud en Málaga: Desde el siglo XVI al XIX”, Jábega, 14, Málaga, pp. 46-62.

DuRÁn DE LA RÚA, Nelson (1979), La Unión Liberal y la modernización de la España isabelina. Una convivencia frustrada. 1854-1868, Akal, Madrid.

Erice, Francisco, (1995), Propietarios, comerciantes e industriales. Burguesía y desarrollo capitalista en la Asturias del siglo XIX (1830-1885), Universidad, Oviedo.

FAes DíAz, Enrique (2009), "El marqués de Comillas: un banquero camino del altar", Historia Social, 64, pp. 121-137.

García Montoro, Cristóbal (1978), Málaga en el comienzo de la industrialización: Manuel Agustín Heredia (1786-1846), Universidad, Córdoba.

Guerola, Antonio (1995), Memorias del gobernador Antonio Guerola, Málaga 1857-1863, Guadalquivir, Sevilla.

JACOBSON, Stepnen (2009), "Francisco Fontanellas: el comerciante-banquero en la época del capitalismo romántico", Historia Social, 64, 53-78.

Jiménez Quintero, José Antonio (1977), "El triángulo financiero. Heredia-LariosLoring”, Jábega, 19, pp. 42-45.

KocKA, Jürgen (2000), "Burguesía y sociedad burguesa en el siglo XIX. Modelos europeos y peculiaridades alemanas”, en J. M. a Fradera y J. Millán (eds.), Las burguesías europeas del siglo XIX, Universitat, Valencia.

López García, José Miguel, (2016), “El mercado de esclavos en Madrid a finales del Antiguo Régimen, 1701-1830”, Historia social, 85, pp. 45-62.

McDonogh, Gary (1989), Las buenas familias de Barcelona. Historia social de poder en la era industrial, Omega, Barcelona.

Mesa, Roberto (1967), El colonialismo en la crisis del XIX español, Ciencia Nueva, Madrid.

Morales Muñoz, Manuel (2010), “Loring Oyarzábal, Jorge Enrique”, en D. CARo Cancela (dir.), Diccionario biográfico de parlamentarios de Andalucía (1810-1869), Centro de Estudios Andaluces, Sevilla, pp. 156-159.

- (1983) "El Banco de Málaga: factor de descapitalización de la economía malagueña", Jabega, 41, pp. 53-64.

Morilla CRitz, José (1975), Acumulación de capital, banca y ferrocarriles en Málaga. Siglos XVIII y XIX, Universidad, Málaga. 
PAReJo, Antonio (1984), "Protocolos notariales e historia industrial: algunas posibilidades metodológicas", Baetica. Estudios de Arte, Geografía e Historia, 7, pp. 337-374.

Piqueras Arenas, José Antonio (ed.) (1992), La Revolución Democrática (18681874). Cuestión social, colonialismo y grupos de presión, Ministerio de Trabajo y Seguridad Social, Madrid.

— (1998), "Negocios y política en el siglo XIX español”, en J. Paniagua y J. A. Piqueras (eds.), Poder económico y poder político, UNED Alcira Valencia y Fundación Historia Social, Valencia.

Piqueras Arenas, José Antonio y Sebastiá Domingo, Enric (1991), Agiolistas negreros y partisanos, Edicions Alfons el Magnànim, Valencia.

Pons, Anaclet y Serna, Justo (1992), La ciudad extensa. La burguesía comercial financiera en la Valencia de mediados del XIX, Diputación, Valencia,

- (2006) Diario de un burgués. La Europa del siglo XIX vista por un valenciano distinguido, Los libros de la memoria, Valencia.

- (2012) Los triunfos del burgués. Estampas valencianas del Ochocientos, Tirant Humanidades, Valencia.

Ramos Frendo, Eva M. (2000), Amalia Heredia Livermore, Marquesa de CasaLoring, Universidad, Málaga.

Rodrigo y Alharilla, Martín (1998), "Negocios y política en el siglo XIX español”, en J. Paniagua y J. A. Piqueras (eds.), Poder económico y poder político, UNED y Fundación Historia social, Valencia, pp. 81-112.

Rodrigo, Martín y JACOBSON, Stephen (coords.) (2009), "La formación del banquero moderno. Introducción”, Historia Social, 64, pp. 47-52.

Sierra Alonso, María (1990), "Empresarios y políticos en la Sevilla de la Restauración: La familia Ybarra", Espacio, Tiempo y Forma, Serie V, pp. 143-158.

- (2009), "Los Ibarra política y empresa en la Restauración", Andalucía en la Historia, 26.

SCHumpeter, Josep (1976), Teoría del desenvolvimiento económico. Una investigación sobre ganancias, capital, crédito e intereses y ciclo económico, Fondo de Cultura Económica, México. 